\title{
Dynamic Modulus Master Curve Construction Using Christensen-Anderson-Marasteanu (CAM) model
}

\author{
Bouraima Mouhamed Bayane ${ }^{1,2}$, Enhui Yang ${ }^{1,2}$, Qiu Yanjun ${ }^{1,2}$ \\ ${ }^{1}$ School of Civil Engineering, Southwest Jiaotong University, Chengdu, Sichuan 610031, China. \\ ${ }^{2}$ Key Laboratory of Highway Engineering, Sichuan Province, Southwest Jiaotong University, Chengdu, Sichuan \\ 610031. China.
}

\begin{abstract}
Dynamic modulus is a fundamental property used in most mechanistic analysis of pavement response as well as material input for design of flexible pavement. Corres pondingly, the $\mathrm{E}^{*}$ of HMA master curve incorporated time and temperature effects. The aim of this study is to obtain dynamic modulus and phase angle data using the Christensen-Anderson-Marasteanu (CAM) model based on master curve. Samples were prepared according to the AASHTO TP 62-03 Standard Test Method for Determining Dynamic Modulus of Hot-Mix Asphalt Concrete Mixtures. The results show that the dynamic modulus is decreasing with increase of temperature for all mixtu res while it is opposite trend with the phase angle. In terms of resistance of rutting, the JAPAN AC-20 is a good potential mix at frequency of 25 and $10 \mathrm{~Hz}$ while USA and JAPAN AC-13 mixes are good for fatigue resistance at same frequency respectively. From the Goodness-of-fit statistics, all the mixture gave an excellent correlation when $\mathrm{R}^{\wedge} 2 \geq 0.90$ and $\mathrm{Se} / \mathrm{Sy} \leq 0.35$. Nonetheless, the correlation coefficient $\mathrm{R}^{\wedge} 2$ is not always a reliable coefficient to measure the Goodness-of-fit for nonlinear regression analysis. Furthermore, they may have local or overall biases in the predictions that can reduce significantly its accuracy under certain conditions. Keywords - Dynamic modulus, phase angle, master curve, CAM model, Goodness -of-fit
\end{abstract}

\section{INTRODUCTION}

Dynamic modulus $\left(\left|\mathrm{E}^{*}\right|\right)$ is one of the important parameter defining the response of Hot Mix Asphalt (HMA) mixtures in flexible pavement systems since they are sensible to temperature and the rate of load. It is also the primary HMA material property input at all three hierarchical levels in the new Mechanistic Empirical Pavement Design Guide (MEPDG) developed under National Cooperative Highway Research Program (NCHRP) 1-37A for the American State Highway and Transportation Officials (AASHTO) [1]. Moreover, it is a leading candidate for the Simple Performance Test (SPT) recommended by the NCHRP 9-19 [2] and has been recommended as a potential quality control-quality assurance parameter [3]. Various rheological models for asphalt and asphalt mixtures have been studied over the last several decades [4-5]. In order to describe those rheological properties, road engineering researchers have studied a lot of representative models such as: the Power Law model, CAS model, DS model, CA model, but these models cannot appropriately describe the rheological properties of asphalt mixtures [6-8]. So in 2001 based on the CA model, ZENG et al. [9] put forward a clear physical meaning of the CAM (ChristensenAnderson-Marasteanu) model, the model is suitable for describing the matrix asphalt, modified asphalt and asphalt mixture while most models are concentrated on asphalt. It can describe the rheological properties of asphalt and asphalt mixture. The CAM model is an improvement on the CA model and its parameters can describe well the viscoelastic characteristics of asphalt and asphalt mixtures providing a reliable basis for material analysis performance evaluation and structure calculation with considerable engineering value. The CAM model is not only for characterizing asphalt binders and mixture, but it is also advantageous for several different load modes. Its parameters have unambiguous meanings in physics .This model is used to describe the rheological behavior of mixtures based on the master curves of dynamic modulus. The CAM model is used based on the wholetemperature-whole-frequency master curve, whose frequency or temperature range covers the whole range of the engineering application and even tends to utmost state at high frequency or low frequency. This research is aims to investigate the effect of aggregate gradation from different countries on the dynamic modulus of asphalt mixtures laid under the railway, obtain the variation of the dynamic modulus and phase angle with frequency, analyze the influence of temperature and frequency on the viscoelastic performance of asphalt mixtures and finally find the master curve of different mixtures. 
Bouraima Mouhamed Bayane. Int. Journal of Engineering Research and Application www.ijera.com ISSN: 2248-9622, Vol. 7, Issue 1, (Part -5) January 2017, pp.53-63

\section{MATERIALS}

SBRII-A modified asphalt is used in this study. Table 1 summarizes the physical properties of this asphalt. The design limits and gradation from different countries used in this study of asphalt concrete mixture are presented in Table 2

Table 1 Physical properties of SBR- II-A modified

\begin{tabular}{|c|c|c|c|c|c|}
\hline \multicolumn{2}{|l|}{ Number } & Test it ems & Unit & Design & $\begin{array}{l}\text { Test } \\
\text { results }\end{array}$ \\
\hline \multicolumn{2}{|l|}{1} & Density & $\mathrm{g} / \mathrm{cm} 3$ & 1 & 1.0223 \\
\hline \multicolumn{2}{|l|}{2} & $\begin{array}{l}\text { Penetration } \\
\left(25^{\circ} \mathrm{C}, 100 \mathrm{~g}, 5 \mathrm{~s}\right)\end{array}$ & $0.1 \mathrm{~mm}$ & $>100$ & 108.5 \\
\hline \multicolumn{2}{|l|}{3} & $\begin{array}{l}\text { Penetration } \\
\text { index PI }\end{array}$ & I & K-1.0 & 0.91 \\
\hline \multicolumn{2}{|l|}{4} & $\begin{array}{l}\text { Ductility } \\
\left(5 \mathrm{~cm} / \mathrm{min}, 5^{\circ} \mathrm{C}\right)\end{array}$ & $\mathrm{cm}$ & $\nless 60$ & 127 \\
\hline \multicolumn{2}{|l|}{5} & $\begin{array}{l}\text { Softening Point } \\
(\mathrm{R} \& \mathrm{~B})\end{array}$ & ${ }^{\circ} \mathrm{C}$ & $\nless 45$ & 52.2 \\
\hline \multicolumn{2}{|l|}{6} & Wax content & $\%$ & $\ngtr 2.2$ & 1.69 \\
\hline \multicolumn{2}{|l|}{7} & Flash point & ${ }^{\circ} \mathrm{C}$ & K230 & 271 \\
\hline \multicolumn{2}{|l|}{8} & Solubility & $\%$ & $\$ 99$ & 99.88 \\
\hline \multicolumn{2}{|l|}{9} & $\begin{array}{l}\text { Sticky } \\
\text { toughness }\end{array}$ & N.m & $\nless 5$ & 7.1 \\
\hline \multicolumn{2}{|l|}{10} & Toughness & N.m & $\nless 2.5$ & 5.8 \\
\hline \multirow{3}{*}{$\begin{array}{l}\text { RTFOT } \\
\text { Post } \\
\text { residue }\end{array}$} & 11 & Mass loss & $\%$ & $\ngtr \pm 1$ & -0.829 \\
\hline & 12 & $\begin{array}{l}\text { Penetration ratio } \\
\left(25^{\circ} \mathrm{C}\right)\end{array}$ & $\%$ & $\nless 50$ & 70.6 \\
\hline & 13 & $\begin{array}{ll}\text { Residual } & \\
\text { ductility } \quad\left(5^{\circ} \mathrm{C}\right.\end{array}$ & $\mathrm{cm}$ & \$30 & 88.8 \\
\hline
\end{tabular}

Table 2 Recommended gradation from different countries

\begin{tabular}{|l|l|l|l|l|}
\hline & $\begin{array}{l}\text { United } \\
\text { State of } \\
\text { America }\end{array}$ & $\begin{array}{l}\text { Japan } \\
\text { AC-13 }\end{array}$ & $\begin{array}{l}\text { Japan } \\
\text { AC-20 }\end{array}$ & $\begin{array}{l}\text { South } \\
\text { Korea }\end{array}$ \\
\hline Open size & \multicolumn{1}{|l|}{ Passing(\%) } & \multicolumn{1}{|l|}{} \\
\hline 37.5 & 100 & & & \\
\hline 26.5 & $90-100$ & & 100 & \\
\hline 19 & $78-95$ & 100 & $95-100$ & 100 \\
\hline 16 & $68-87$ & - & - & - \\
\hline 13.2 & $56-80$ & $95-100$ & $70-90$ & $92-97$ \\
\hline 9.5 & $42-68$ & - & - & $80-92$ \\
\hline 4.75 & $29-57$ & $55-70$ & $35-55$ & $51-68$ \\
\hline 2.36 & $19-45$ & $35-50$ & $20-35$ & $30-48$ \\
\hline 1.18 & $14-34$ & - & - & - \\
\hline 0.6 & $10-25$ & $18-30$ & $11-23$ & $17-30$ \\
\hline 0.3 & $5-17$ & $10-21$ & $5-16$ & $11-19$ \\
\hline 0.15 & $3-10$ & $6-16$ & $4-12$ & $7-11$ \\
\hline 0.075 & $1-7$ & $4-8$ & $2-7$ & $3-7$ \\
\hline$<0.075$ & - & - & - & - \\
\hline
\end{tabular}

\section{SAMPLE PREPARATION AND TEST METHOD}

\section{Sample Preparation}

Samples for dynamic modulus were prepared by mixing asphalt and aggregates. Prior to the mixture, aggregates are heated for at least 4 hours in oven at $180^{\circ} \mathrm{C}$ to dry them to maximum extent and asphalt is kept in oven at $160^{\circ} \mathrm{C}$ for 2 hours at an appropriate mixing temperature. Initially, during mixing; aggregates and asphalt are mixed together for 90 seconds, and then filler was included in the mixture and mix at 90 seconds. After mixing, the mixture was poured onto the mold and samples were compacted at $150{ }^{\circ} \mathrm{C}$ in a $150 \mathrm{~mm}$ diameter to a height of $170 \mathrm{~mm}$ by using a gyratory compactor. After compaction, the sample was extruded from the compaction mold, labelled and allowed to cool to room temperature. The compacted sample were cored and trimmed to obtain a standard $150 \mathrm{~mm}$ height and 100 diameter test sample with different gradation air voids.

\section{Test Method}

The dynamic resilient modulus testing is a cyclic compressive test performed on cylindrical asphalt specimens with the dimensions of $100 \mathrm{~mm}$ diameter (4 in) and $150 \mathrm{~mm}$ height (6 in) as mentioned in the section above. The test was performed according to the AASHTO TP 62-03 Standard Test Method for Determining Dynamic Modulus of Hot-Mix Asphalt Concrete Mixtures. In this test a sinusoidal axial compressive load is applied to the cylindrical specimen at a sweep of loading frequencies. During testing, the Universal Testing Machine (UTM) system measures the vertical stress and the resulting vertical compression strain. The dynamic resilient modulus is calculated by dividing the peak to peak vertical compressive stress to the peak-to-peak vertical strain. Six frequencies $(0.1,0.5,1,5,10$ and $25 \mathrm{~Hz})$ and four temperatures $\left(-40,-20,-11\right.$ and $\left.18^{\circ} \mathrm{C}\right)$ were selected for the test. The tests were conducted within the linear viscoelastic stress level where the strain was controlled between $50 \sim 150 \mu \varepsilon$. The specimens were conditioned in the environmental chamber for at least two hours before testing. In this testing configuration, the specimen is placed centered on the steel plates. The LVDTs are fixed to the glued nuts and, the top steel plate is centered on the specimen to ensure centric loading. The actuator is gradually lowered until it touches slightly the top plate. Once the preparation and mounting of the asphalt cylinder specimen is finished the test is controlled entirely by the CDAS. The process of manufacturing $\mathrm{E}^{*}$ specimens is shown in Fig. 1

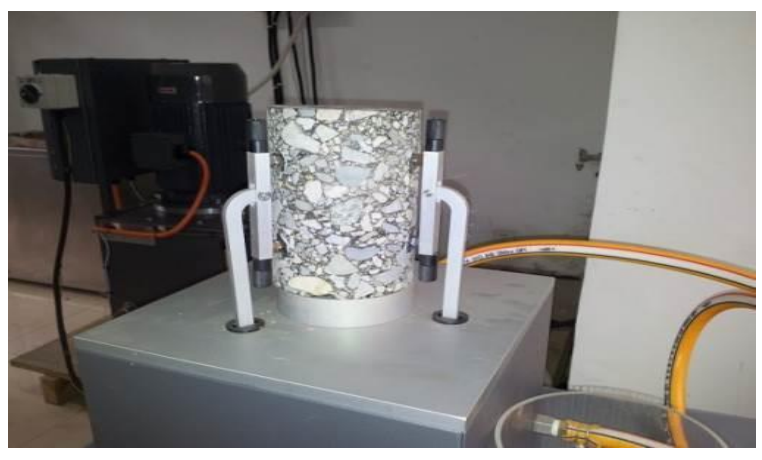

a) $\quad$ Fixing Studs 


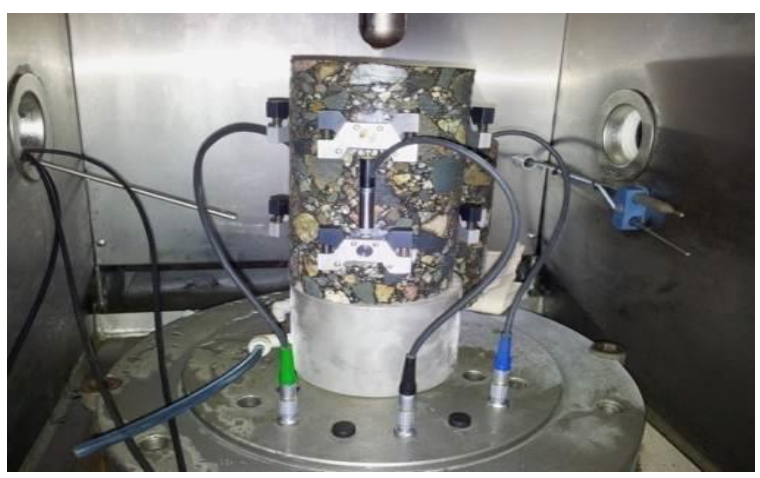

b) Putting LVDTs

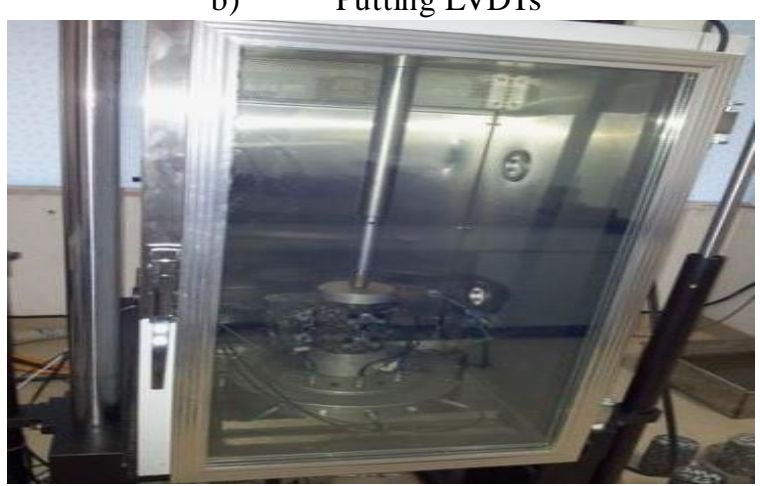

c) Dynamic loading test

Figure 1: The process of manufacturing $E^{*}$ specimens.

\section{RESULTS AND DISCUSSION}

\section{Dynamic modulus}

Fig. 2 presents the variation of the dynamic modulus with temperatures and frequencies for the four mixtures evaluated in this study. As can be seen from the Fig. 2, the $E^{*}$ values increased with the increase of loading frequency at a constant temperature and vice versa. This fact illustrated the time dependency of viscoelastic material which states that the viscoelastic materials like asphalt concrete mixtures behave strongly against the slower loading rate than they do against the faster loading rate. Similarly, the $\mathrm{E}^{*}$ value of the as phalt concrete specimens decreased with the increase of test temperature and vice versa. This fact illustrated the temperature dependency of viscoelastic materials which states that the viscoelastic materials behave strongly at low temperature. The reason behind the temperature dependency of viscoelastic materials is the dominance of viscous behavior at high temperature and that of elastic behavior at low temperature. In addition, the measured $\mathrm{E}^{*}$ increases with the increase in nominal maximum aggregate sizes (NMAS) for the aggregate from Japan (see Figs. 3 and 4) at both low level (low temperature and high frequency) and high level (high temperature and low frequency). The dynamic modulus of the four mixtures has been compared at diffe rent temperature and the results are displayed in Fig. 5. From Fig. 5 it can be seen that the dynamic modulus of JAPAN AC-20 mixture is the highest at low and high temperatures $\left(-40\right.$ and $18^{\circ} \mathrm{C}$ ) whereas JAPAN AC-13 mix exhibits the lowest dynamic modulus at both $\left(-11\right.$ and $\left.18^{\circ} \mathrm{C}\right)$. USA mixture exhibits the highest dynamic modulus at $-20{ }^{\circ} \mathrm{C}$ while at $-40^{\circ} \mathrm{C}$; its dynamic modulus is the lowest one. Figs 6 and 7 present the decrease in the $E^{*}$ with an increase in temperature at high and low loading frequency respectively. This is due to the temperature dependency of viscoelastic materials explain above.
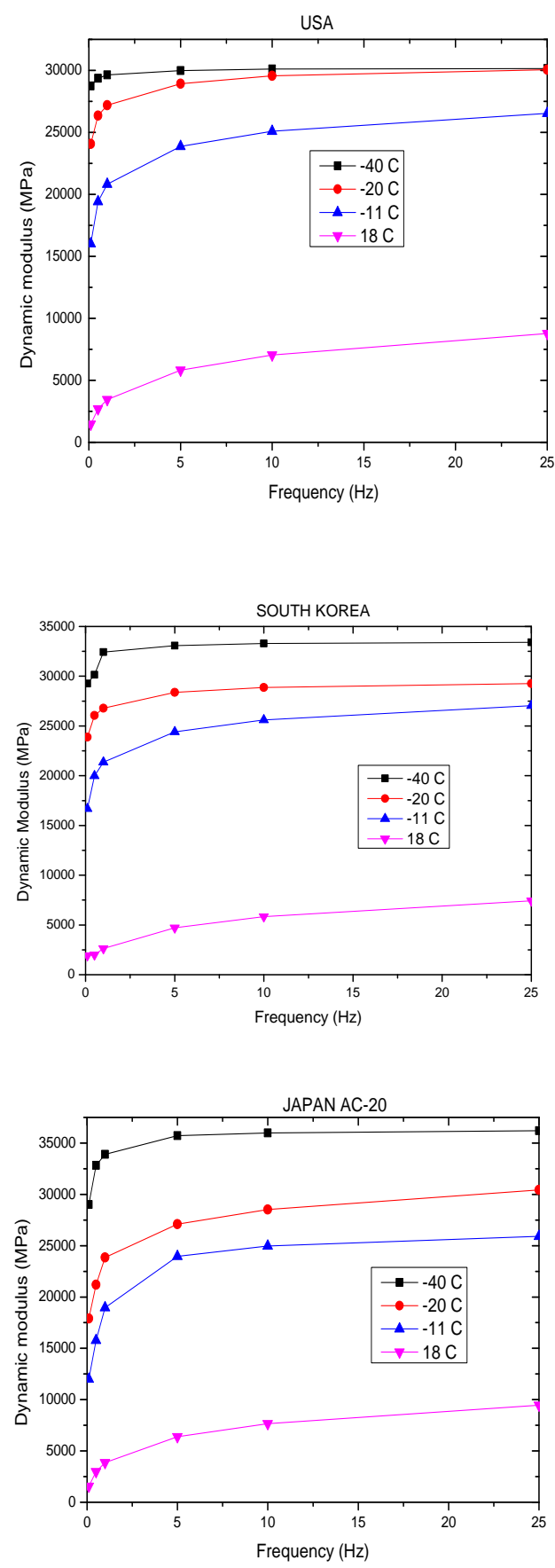
Bouraima Mouhamed Bayane. Int. Journal of Engineering Research and Application www.ijera.com ISSN: 2248-9622, Vol. 7, Issue 1, (Part -5) January 2017, pp.53-63

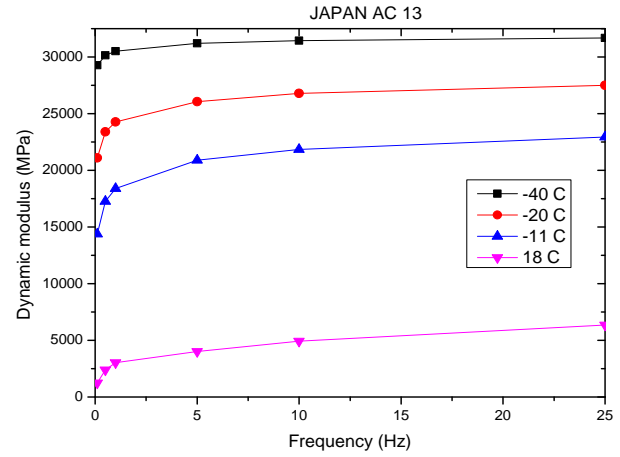

Figure 2: Variation of the dynamic modulus with temperatures and frequencies for the four mixtures

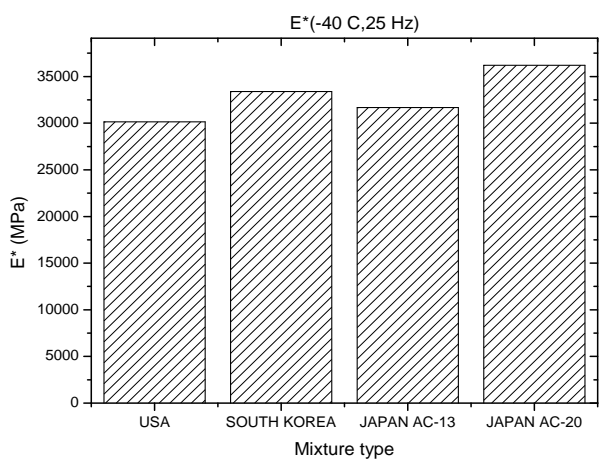

Figure 3: Comparison of $\mathrm{E}^{*}$ at low temperature and high frequency

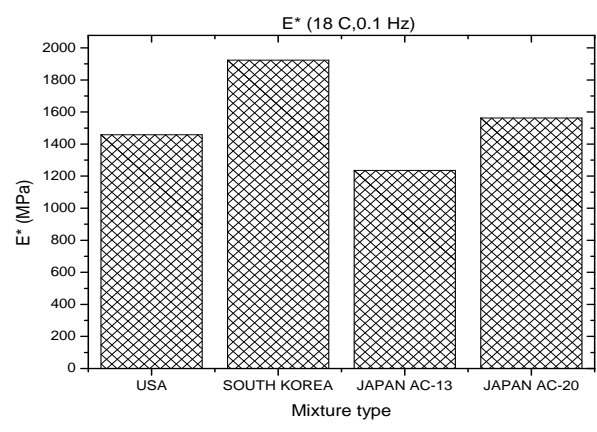

Figure 4: Comparis on of $\mathrm{E}^{*}$ at high temperature and low frequency
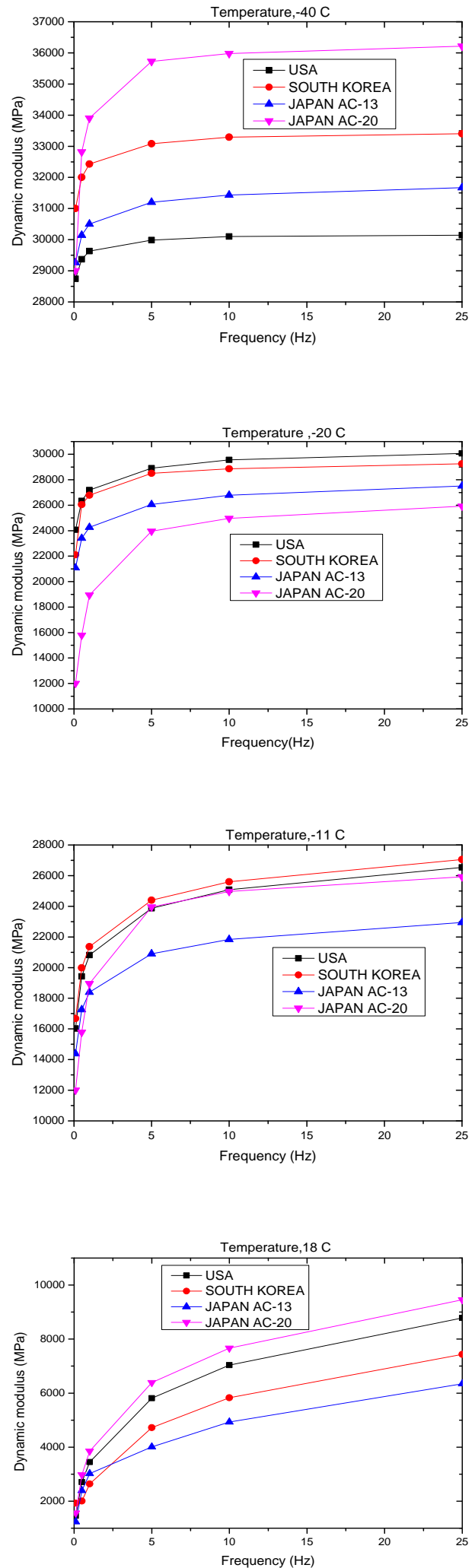

Figure 5: Dynamic modulus of the four mixtures at different te mperature. 


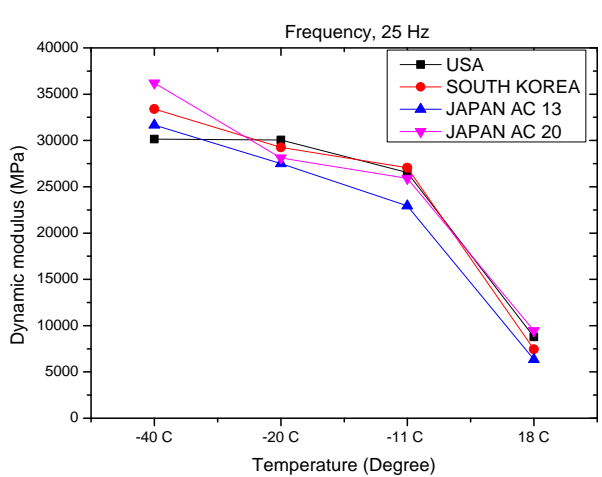

Figure 6: Variation of dynamic modulus with temperature at high loading frequency.

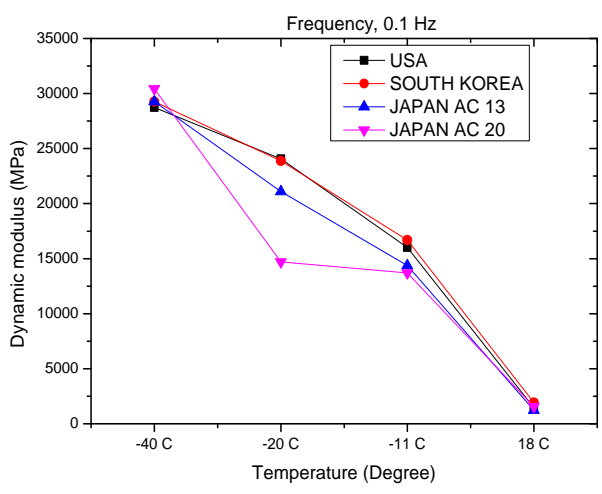

Figure 7: Variation of dynamic modulus with temperature at low loading frequency.

\section{Phase angle}

The second parameter determined from dynamic modulus test was the phase angle. Phase angle is the angle between peak strain and peak stress, which directly indicate the viscoelastic property of asphalt mixtures. For materials with viscoelastic characteristic, the range of the phase angle is always between $0^{\circ}$ and $90^{\circ}$. For those two extreme points, $\beta=0^{\circ}$ corresponds to a purely elastic material and $\beta=90^{\circ}$ corresponds to a purely viscous material. Fig.8 illustrates the phase angle for all the mixtures at different frequencies and test temperatures. As shown in the Fig. 8, the measured phase angle increased when the frequency decreased and when the temperature increased. In addition, the phase angle of the four mixtures has been compared at different temperature and the results are displayed in Fig. 9. It can be seen from the Fig.9 that the phase angle of USA mix is the highest and the lowest at low temperature $-40^{\circ} \mathrm{C}$ and at $-20{ }^{\circ} \mathrm{C}$ respectively. JAPAN AC-20 and JAPAN AC-13 exhibit the highest phase angle respectively at $-20^{\circ} \mathrm{C}$ and $18^{\circ} \mathrm{C}$. JAPAN AC- 20 has the lowest phase angle at $-40^{\circ} \mathrm{C}$ and $18^{\circ} \mathrm{C}$. At $-11^{\circ} \mathrm{C}$, SOUTH KOREA has the lowest phase angle. Figs 10 and 11 present the variation in the phase angle of asphalt mixtures with temperature at high and low frequency respectively. The trend is increasing with increase in temperature for all the mixtures. Rutting and fatigue cracking can be characterized using the dynamic modulus $\left|E^{*}\right|$ and phase angle $(\beta)[\mathbf{1 0}]$. The dynamic modulus values were obtained at $-11^{\circ} \mathrm{C}$ and $18^{\circ} \mathrm{C}$, respectively because rutting usually occurs during summer at high temperature condition and fatigue cracking is a common phenomenon at intermediate pavement service temperature. The frequency of $10 \mathrm{~Hz}$ and 25 $\mathrm{Hz}$ was selected for both parameters because it is most closely corresponds to vehicle speed of about $64 \mathrm{Km} / \mathrm{h}$ and over $160 \mathrm{Km} / \mathrm{h} \mathrm{[11]} \mathrm{and} \mathrm{dynamic}$ modulus data at $18^{\circ} \mathrm{C}$ and $-11^{\circ} \mathrm{C}$ have been used. Higher values of this parameter indicate stiffer mixtures that have good rutting resistance. $E^{*}$ alone was also suggested as an indicator for rutting resistance of asphalt mixtures. For Fatigue evaluation, the recommended parameter was $\left|E^{*}\right|$ $\sin \beta$. Figs 12 and 13 illustrate the rutting factor and fatigue factor of different mixes. Lower fatigue factor $\left(\left|E^{*}\right| \sin \beta\right)$ is an indication of better performance against fatigue while higher rutting factor $\left(\mid E^{*} / / \sin \beta\right)$ shows greater rutting resistance [11].

It can be seen that from the Fig. 12 above that AC-20 asphalt mixture shows better rutting resistance with higher rutting factor at $18^{\circ} \mathrm{C}$ for both frequencies at $25 \mathrm{~Hz}$ and $10 \mathrm{~Hz}$. At $25 \mathrm{~Hz}$, USA mixture has the lowest fatigue factor at $25 \mathrm{~Hz}$ while at $10 \mathrm{~Hz}, \mathrm{JAPAN}$ AC-13 has the lowest fatigue factor (see Fig. 13). It can be concluded then that USA mixture has better fatigue resistance at $25 \mathrm{~Hz}$ and JAPAN AC-13 at $10 \mathrm{~Hz}$.

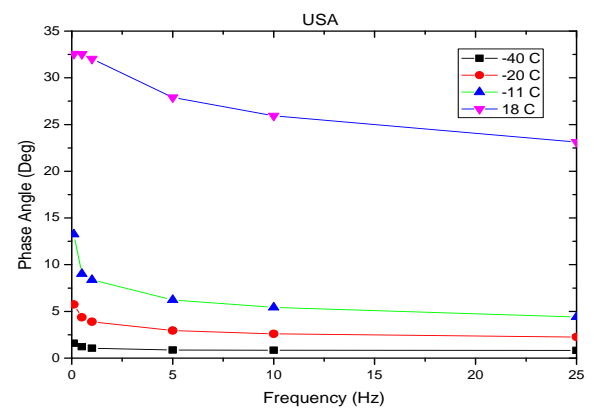


Bouraima Mouhamed Bayane. Int. Journal of Engineering Research and Application www.ijera.com ISSN: 2248-9622, Vol. 7, Issue 1, (Part -5) January 2017, pp.53-63
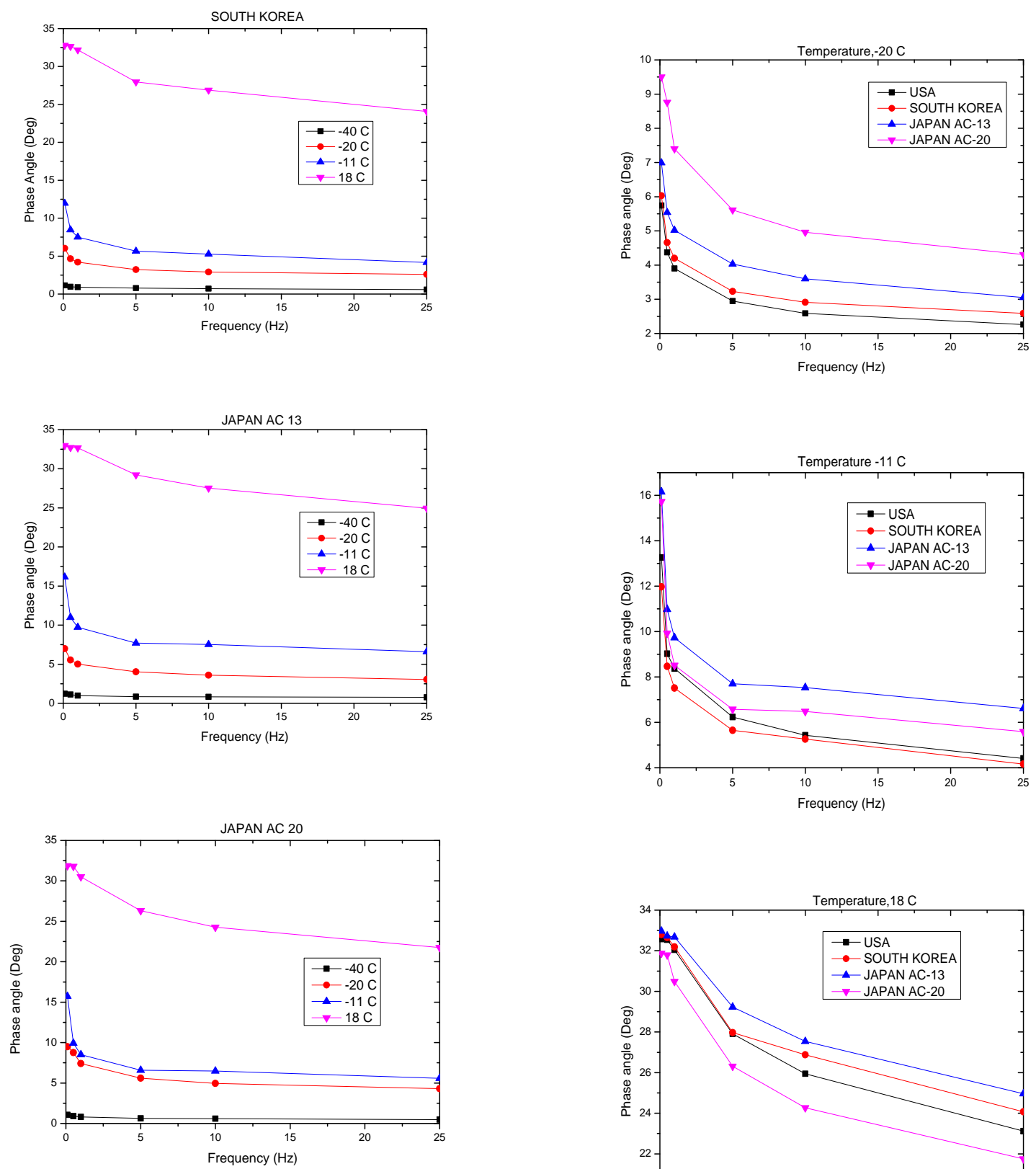

Figure 8: Phase angle of all mixtures at different temperatures and frequencies.

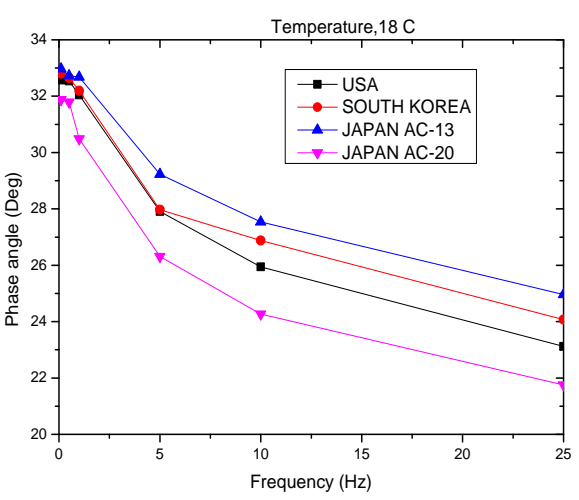

Figure 9: Phase angle of the four mixtures at different te mperature.

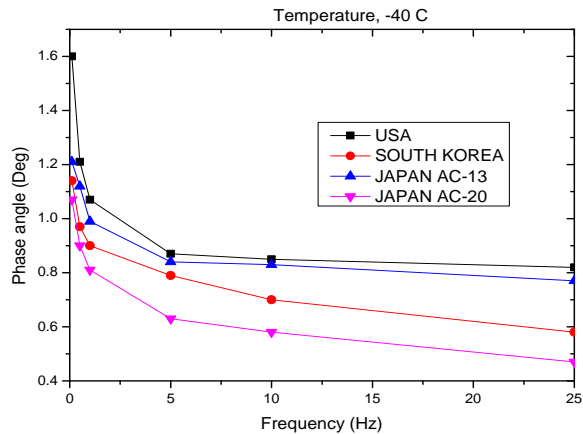




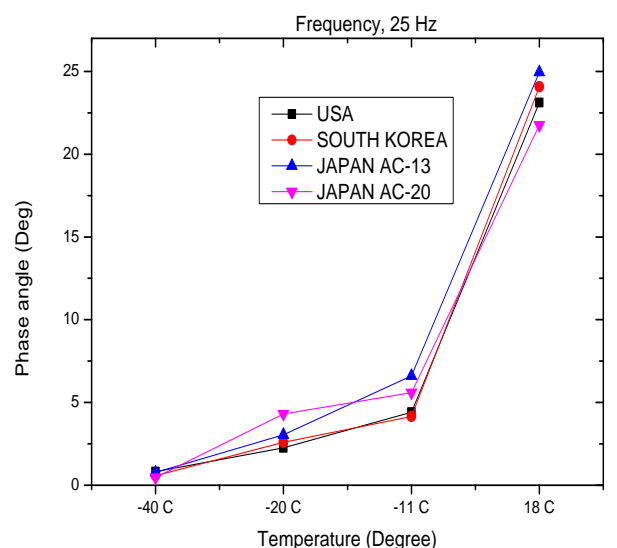

Figure 10: Variation of phase angle with temperature at high loading frequency

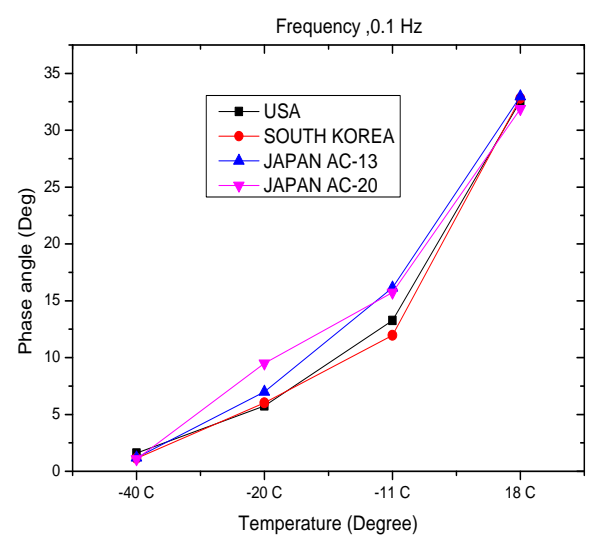

Figure 11: Variation of phase angle with temperature at low loading frequency

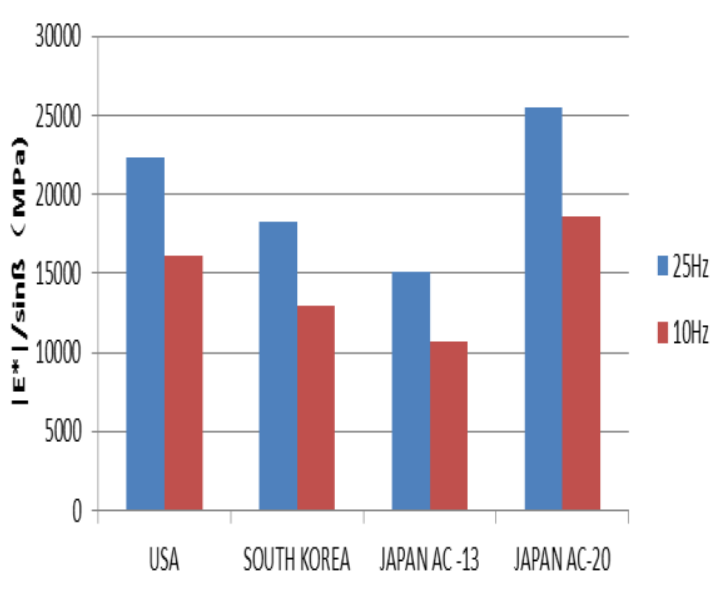

Figure 12: Rutting factor comparison for different mixes at $18^{\circ} \mathrm{C}, 10$ and $25 \mathrm{~Hz}$

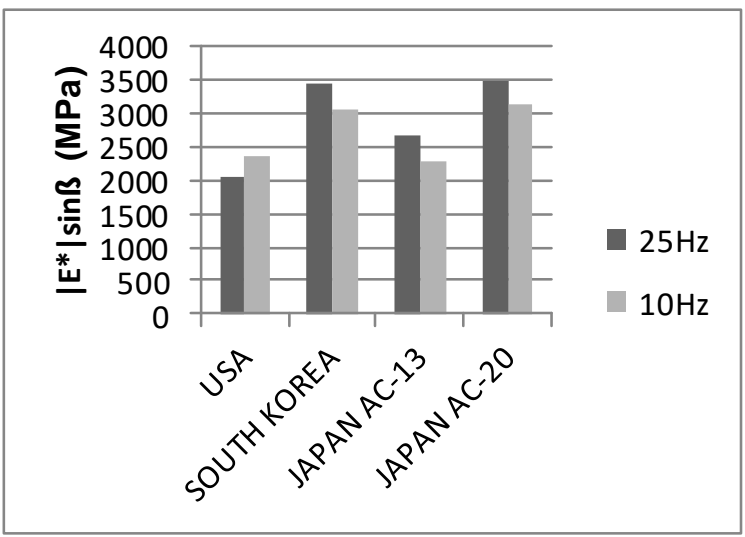

Figure 13: Fatigue factor comparison for different mixes at $-11^{\circ} \mathrm{C}, 10$ and $25 \mathrm{~Hz}$

\section{Master Curve}

Master curves were developed using dynamic modulus $\left(\mathrm{E}^{*}\right)$ values determined at different temperatures and loading frequencies to account for temperature and rate of loading effects on the modulus of asphalt concrete. The temperature dependency of materials is defined by the a mount of shifting required at each Temperature to form it [12]. $\mathrm{E}^{*}$ test results from Universal Testing Machine were used to fit a master curve, produce shift factors, and evaluate predictive equation from which dynamic modulus can be estimated for asphalt mixtures. The shift factors provide the magnitude of data shift for tests at different temperatures relative to a reference temperature. A sigmoid function is fitted to the shifted data to produce the $\mathrm{E}^{*}$ master curve. HMA being a viscoelastic material depends on rate of loading (time) and temperature for characterizing HMA stiffness. Here the timetemperature shift principle is used to translate the relationships from three dimensions to two dimensions and prolong the frequency or temperature range and the master curve is finally obtained The Williams-Landel-Ferry (WLF) [13] formulation used to express the temperature shift factor in this research as equation (1) below:

$$
\log a_{(T)}=\frac{-C_{1}\left(T-T_{s}\right)}{C_{z}+T-T_{s}}
$$

Where $C_{1}$ and $C_{2}$ are material constant, $\mathrm{T}$ is the test temperature and $T_{\sigma}$ is the reference temperature. Then, Christensen-Anderson-Marasteanu (CAM) model was used to analyze and compare the rheological performances of complex shear modulus of asphalt mixtures using the equation (2).

$$
G^{*}=G_{e}^{*}+\frac{G_{g}^{*}-G_{\varepsilon}^{*}}{\left[1+\left(\frac{f_{q}}{f^{v}}\right)^{k}\right]^{m_{\varepsilon} k}}
$$


Where $G_{e}^{*}$ - the equilibrium modulus representing the minimum modulus which a mixture can offer in shear.

$G_{g}^{*}$ - the maximum asymptotic modulus in shear which represents the response at very high frequencies or very low temperatures at which the binder in a mixture can contribute the most to the mixture modulus.

$f_{0}$ - location parameter indicating the frequency at which the elastic component is approximately equal to the viscous component.

$k, m_{e}$ - shape parameters.

The rheological performances of phase angle of asphalt mixtures have been also analyzed using equation (3) shown below:

$\delta=\delta_{m}\left\{1+\left[\frac{\lg \left(\frac{f t}{f}\right)}{R_{d}}\right]^{Z}\right\}^{-m_{d} / 2}$

Where $\delta_{m}$-the peak value of phase angle or the maximu $m$ value of the phase angle

$R_{d}, m_{d}-$ shape parameters.

$f_{t}$-Frequency corresponding to the highest point of the phase angle.

In this research $-20^{\circ} \mathrm{C}$ is chosen as reference temperature and the shift factors of all the mixtures have been calculated and displayed in Fig. 14. The master curve being a semi-log plot of $\mathrm{E}^{*}$ versus $\log$ reduced time or frequency, plots of master curve of the four mixtures were presented in Figs 15 to 18 . As can be seen from Figs 15 to 18 , the $E^{*}$ master curves for all the mixture show s mooth trends. The same shift factors that were used in the construction of dynamic modulus master curves also may be used to create master curves of phase angle vs. time. The shift factor was applied for each mixture, and the phase angle was plotted against the shifted time. These plots are shown in Figs 19 to 22. The plots indicate that none of the phase angle master curves are smooth. The data appears scattered at the higher test temperature for all mixtures. At low temperatures, the phase angle master curves appeared relatively smooth. As expected, the phase angle follows the behavior of a viscoelastic material; i. e., it decreases as the time decreases (frequency increases).

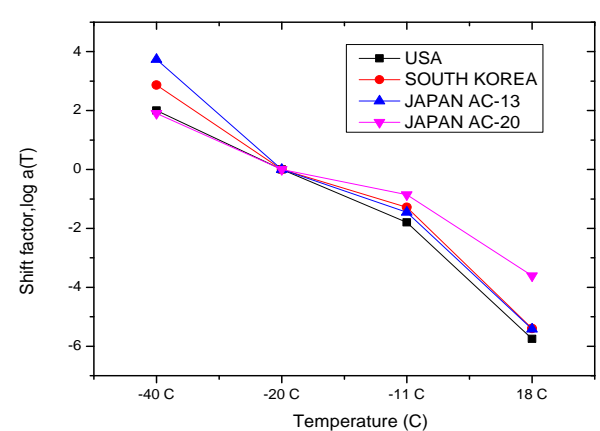

Figure 14: Shift factors versus temperature for all mixtu res

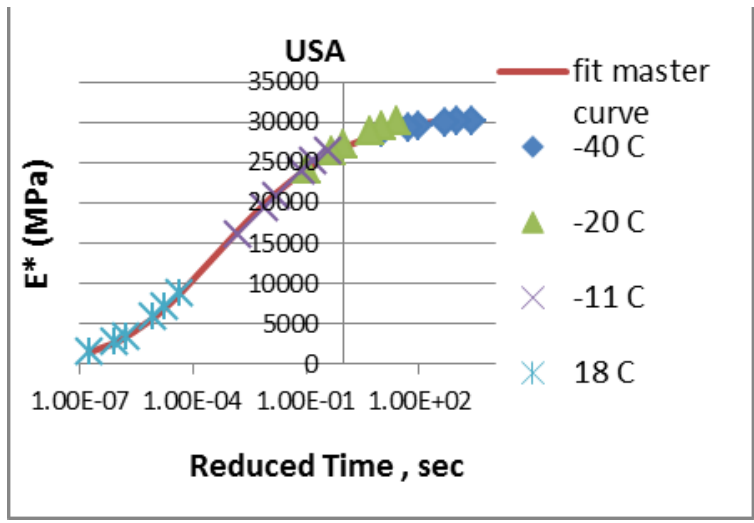

Figure 15: Dynamic Modulus Master Curve of USA mixture using CAM model 
Bouraima Mouhamed Bayane. Int. Journal of Engineering Research and Application www.ijera.com ISSN: 2248-9622, Vol. 7, Issue 1, (Part -5) January 2017, pp.53-63

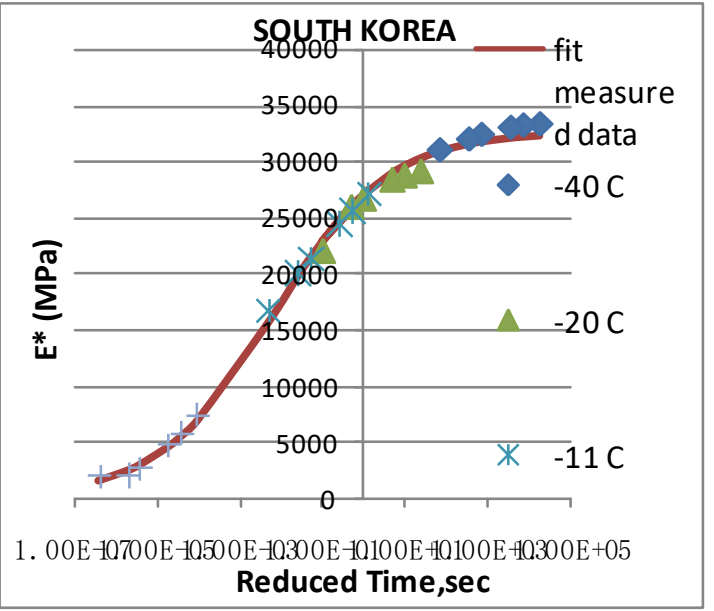

Figure 16: Dynamic Modulus Master Curve of SOUTH KOREA mixture using CAM model

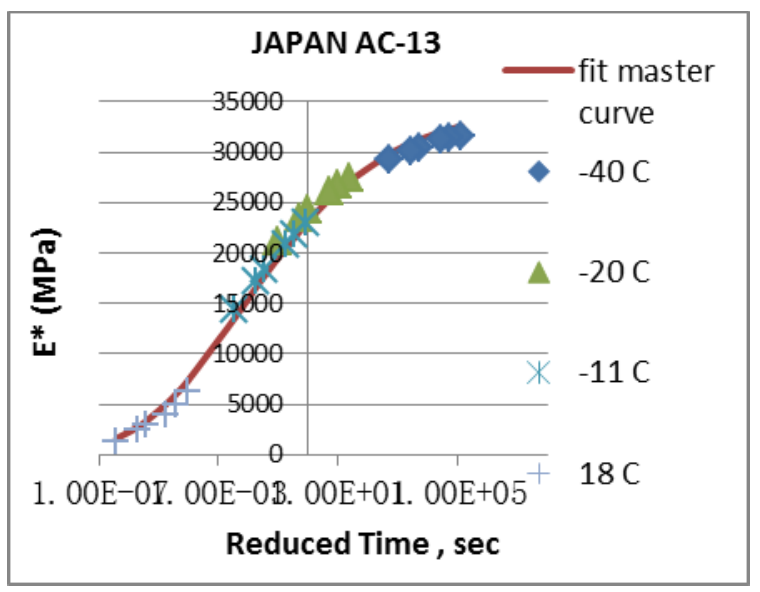

Figure 17: Dynamic Modulus Master Curve of JAPAN AC-13 mixture using CAM model

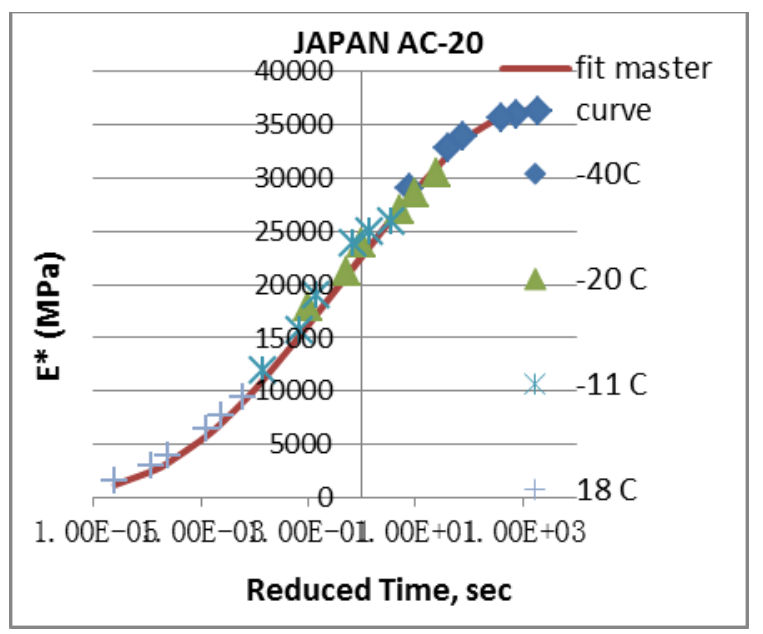

Figure 18: Dynamic Modulus Master Curve of JAPAN AC-20 mixture using CAM model

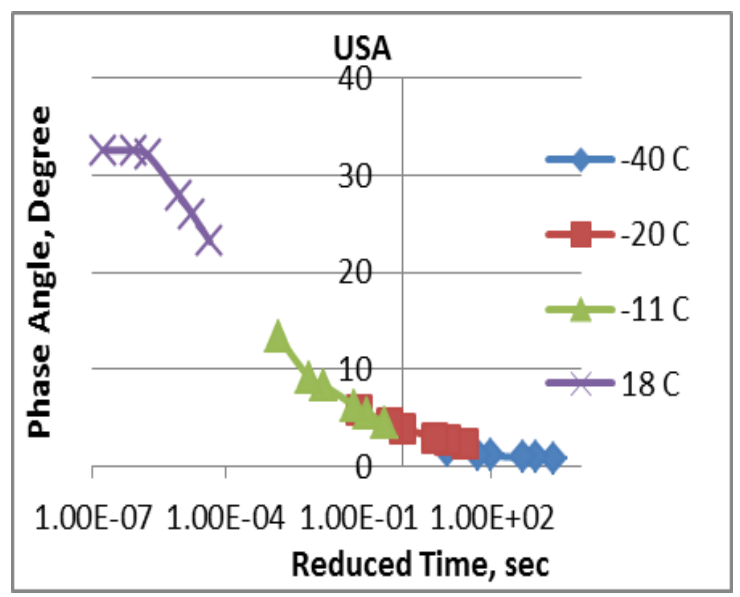

Figure 19: Phase Angle Master Curve for USA mixture using CAM model

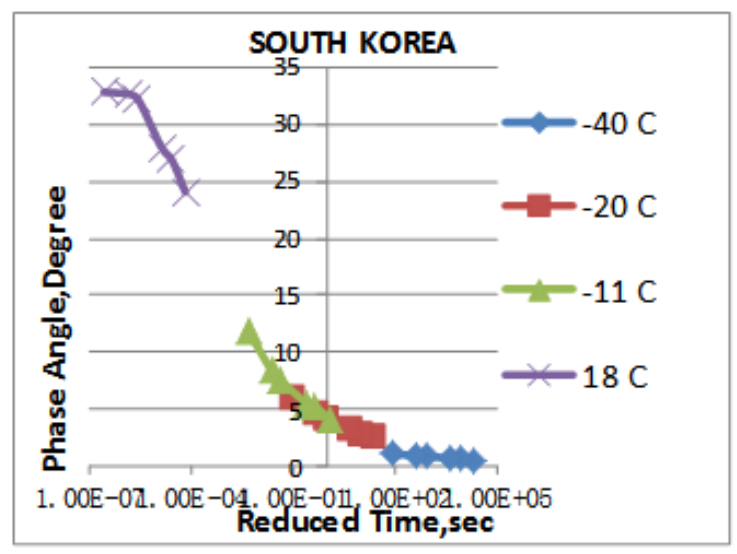

Figure 20 : Phase Angle Master Curve for SOUTH KOREA mixture using CAM model

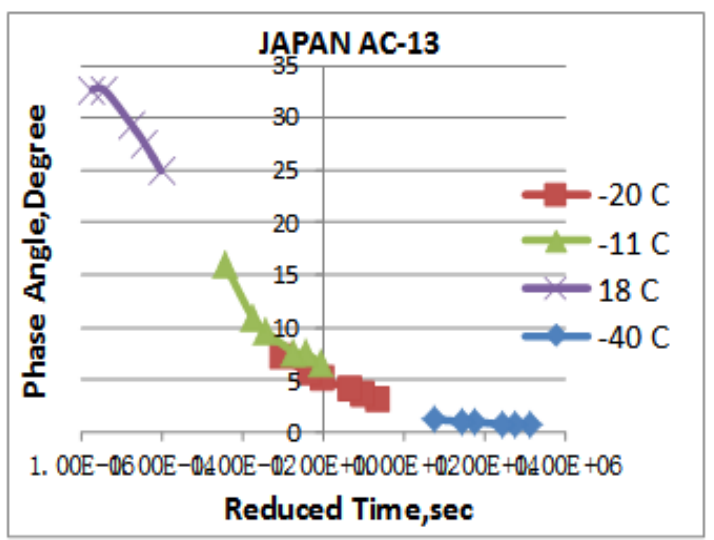

Figure 21: Phase Angle Master Curve for JAPAN AC-13 mixture using CAM model 
Bouraima Mouhamed Bayane. Int. Journal of Engineering Research and Application www.ijera.com ISSN: 2248-9622, Vol. 7, Issue 1, (Part -5) January 2017, pp.53-63

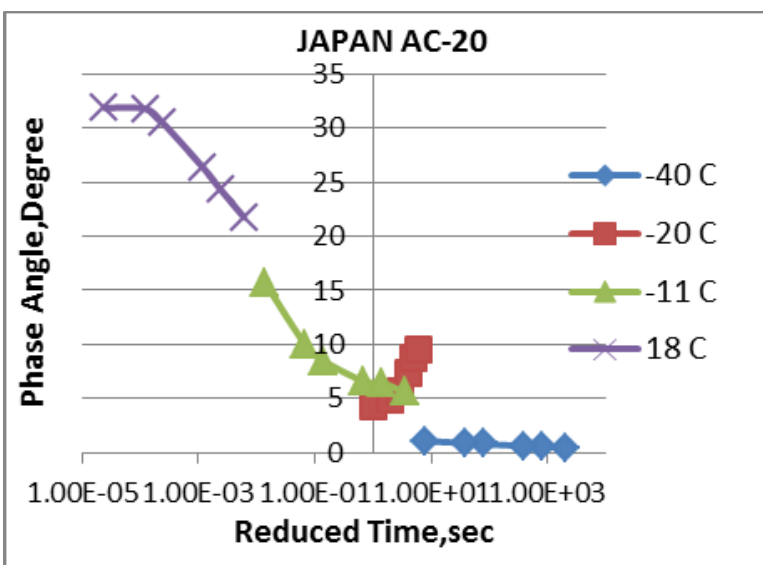

Figure 22: Phase Angle Master Curve for JAPAN AC-20 mixture using CAM model

\section{Goodness-of Fit-Test Statistic}

Statistical methods have been used to determine the Goodness-of-fit between measured and predicted data. From equation (4) to (6) are the standard error ratio, standard error of estimation, standard error of deviation before the final adjusted coefficient of determination, $R^{2}$ established in equation (7).

Standard Error Ratio

$\frac{S_{Q}}{S_{y}}$

Standard Error of Estimation

$S_{e}=\sqrt{\frac{\sum(Y-\hat{\underline{Y}})^{2}}{n-k}}$

Standard Error of Deviation

$S_{y}=\sqrt{\frac{\sum(Y-\bar{Y})^{2}}{n-1}}$

Adjusted Coefficient of Determination

$R^{2}=1-\frac{(n-1)}{(n-k)} \cdot\left[\frac{s_{g}}{s_{y}}\right]^{2}$

Where $\mathrm{n}$ is sample size, $\mathrm{k}$ is the number of independent variables in the model, $\mathrm{Y}$ is a measured data $a_{T}, \bar{Y}$ is a predicted $a_{T}$ and $\bar{Y}$ is the mean value of $a_{T}$.

The coefficients are previously defined for the perfect fit, $R^{2}=1$. The criteria for $\frac{s_{g}}{s_{y}} \ll 0.35$ is considered excellent and $R^{2} \geq 0.90$ is also considered excellent [14]. The results of goodnessof-fit test for all the four mixtures are shown in Table 3.

Table 3 Su mmary of the $\frac{s_{g}}{s_{y}}, R^{2}$ Goodness-of -fit for all mixtures

\begin{tabular}{|l|l|l|}
\hline $\begin{array}{l}\text { Mixture } \\
\text { SOURCE }\end{array}$ & $\frac{S_{e}}{S_{y}}$ & $R^{2}$ \\
\hline USA & 0.040 & 0.9984 \\
\hline $\begin{array}{l}\text { SOUTH } \\
\text { KOREA }\end{array}$ & 0.054 & 0.997 \\
\hline JAPANAC-13 & 0.077 & 0.9940 \\
\hline JAPANAC-20 & 0.080 & 0.9934 \\
\hline
\end{tabular}

From the Table 3, all the mixtures gave an excellent correlation when $R^{2} \geq 0.90$. Standard error ratio also shows an excellent correlation coefficient when $\frac{s_{q}}{s_{y}} \leq 0.35$. Even so, the correlation coefficient $\left(R^{2}\right)$ is not always a reliable coefficient to measure the Goodness-of-fit for nonlinear regression analysis according to Yusoff et al [14]; there may be either overall or local biases in predictions that can cause significant reductions in accuracy under certain conditions [15].

\section{CONCLUSION}

In this study the dynamic modulus and phase angle were determined for four different asphalt mixtures. Thirty two specimens from four mixtures were tested under four different temperatures and six frequencies. Based on the test data, master curves for each mixture were constructed, and the Goodness-of-fit statistics between measured and predicted dynamic modulus was evaluated. The following conclusions can be drawn from the tests.

- Under a constant test frequency, the $\mathrm{E}^{*}$ decreases with the increase of the test temperature for the same mixture. Under a constant test temperature, the $\mathrm{E}^{*}$ increases with the increase of the test frequency, while most of the phase angle data shows the opposite trend.

- Mixes with a $19 \mathrm{~mm}$ NMAS were found to be associated with higher dynamic modulus than those mixes with a $13.2 \mathrm{~mm}$ NMAS for JAPAN asphalt mixture. This trend is because of the stronger stone-to-stone contact among the larger aggregates.

- The $\mathrm{E}^{*}$ master curve show smooth trends, while the phase angle master curve (especially the data obtained at high test temperatures) shows much more scatter. Use of the same shift factors as for the $\mathrm{E}^{*}$ master curves did not result in smooth master curves for phase angle. This means that it is very difficult to obtain accurate test data for phase angle, especially at high test temperatures.

From the Goodness-of-fit test analysis, all the mixtures gave an excellent correlation when $R^{2} \geq 0.90$. Standard error ratio also shows an excellent corre lation coefficient when $\frac{s_{g}}{s_{y}} \leq 0.35$. 


\section{ACKNOWLEDGEMENT:}

This project was supported by the National Natural Science Foundation of Ch ina (Grant No. 51308477).

\section{REFERENCES}

[1.] Rowe, G M., Hakimzadeh, S., Blankenship, P., et al. Evaluation of Aspects of $E^{*}$ Test Using Hot-Mix-Asphalt Specimens with Varying Void Contents. Journal of the Transportation Research Board, Transportation Research Board of the National Academics, Washington, DC, 2009, 164-172.

[2.] Witczak, M, W., Kaloush, K., Pellinen, T., ElBasyouny, M., and Quintus, H, V. Simple performance test fog superpave mix design, NCHRP Report 465, Transportation Research Board. Washington, D.C, 2002.

[3.] Bonaquist, R, F., Christensen, D, W., and Stump, W. Simple performance tester for superpave mix design development and evaluations, NCHRP Report 513, Transportation Research Board, Washington, D.C, 2003.

[4.] Marasteanu, M.O., \& Anderson, D.A. Improved Model for Bitumen Rheological Characterization. Eurobitume WorkshopPerformance Related Properties of Bituminous Binders, Lu xe mbourg, May 1999.

[5.] Stastna, J., Zan zotto, L., Berti, J. How good are some rheological models of dynamics functions of asphalt. Journal of the Association of Asphalt Paving Technologists, 1997, 66 (5): 458-485.

[6.] WU Gang. Study on Structure and Dynamic Viscoelastic Properties of Filled Conductive Polymers, PhD Thesis. Hangzhou: Zhejiang University, 2004.

[7.] CHRSTENSEN D W, ANDERSON D Interpretation of Dynamic Mechanical Test Data for Paving Grade Asphalt Cements. Journal of the Association of Asphalt Paving Technologists, 1992, 61: 67-112.

[8.] MARASTEANU, 0., ANDERSON, D, A.
Improved Model for Bitumen Rheological Characterization EBW. In: Proceedings of Euro bitumen Workshop on Performance Related Properties for Bituminous Binders. Lu xe mbourg: EBW, 1999, 133-134.

[9.] Zeng Meng-lan, Bahia Hussain U, Zhai Huachun, et al. Rheological modeling of modified asphalt binders and mixtures. Journal of the Association of Asphalt Paving Technologists, 2001, 70 (6): 403-435.

[10.] Bhasin A., Button, J. W., Chowdhury, A. Evaluation of simple performance tests on HMA mixtures from the south central United States. Report no. FHWA/TX-03/9-558-1. Texas Transportation Institute, College Station, Texas, 2004.

[11.] Sabahfar N., Aziz, S, R., Hossain, M., Schieber, G Evaluation of Superpave mixtures with high percentages of reclaimed asphalt pavement. In: 93rd Annual meeting of the transportation research board, Washington, DC, 2014.

[12.] ARA Inc. ERES Consultant Division. Guide for Mechanistic-Empirical Design of New and Rehabilitated Pavement Structures-National Cooperative Highway Research Program (NCHRP1-37A Final Report). Transportation Research Board: Washington. DC, 2004.

[13.] Zhang Xiaoning. Viscoelastic mechanics principle and application of asphalt and asphalt mixture, master thesis, (Beijing China Communication Press, 71-86 (in Chinese), 2006.

[14.] Yusoff, N. I., Chailleux, Md., E., and Airey, D. G A Comparative Study of the Influence of Shift Factor Equations on Master Curve Construction. International. Journal of Pavement Research Technology, 2011, 4 (6):324-336.

[15.] Ceylan, H., Schwartz, C. W., Kim, S and Gopalakrishnan, K. Accuracy of Predictive Models for Dynamic Modulus of Hot Mix Asphalt, ASCE Journal of Materials in Civil Engineering, 2009, Vol 21, No 6 *286-293. 